solitary one can sometimes be observed in shallow water close to shore. At night they are often heard jumping near the shore. These fish not infrequently leap into the canoes of people fishing at night with lights (N Wicks, personal communication). It is not surprising, therefore, that an occasional fisherman gets speared by a sharp beak and that deaths occur.

The external wound may appear deceptively trivial. It should be regarded as a stab wound and, therefore, the possibility of internal injury should be borne in mind. Patients speared in the chest or abdomen should be considered for urgent transfer to a hospital with surgical facilities. Little is known about ways of preventing injury by these fish, although placing canoes in a circle and spearing only fish in the central pool of light may lessen the risk.
I thank all those who helped by contributing case histories, including Dr R Dethlefs, ophthalmologist, who sent a detailed case history of one of his patients.

\section{References}

1 Fricke HW. The coral seas. New York: G B Putnams, 1973.

${ }^{2}$ Carcasson RH. A field guide to reef fishes of tropical Australia and the IndoPacific region. Sydney: Collins, 1977.

${ }^{3}$ Munro ISR. The fishes of Papua New Guinea. Port Moresby, Papua New Guinea: Department of Primary Industry, 1967:105-9.

(Accepted 8 September 1981)

\title{
Does the order of second-line treatment in rheumatoid arthritis matter?
}

\author{
M M STEVEN, J A HUNTER, R M MURDOCH, H A CAPELL
}

\begin{abstract}
In a prospective study 88 patients with rheumatoid arthritis who had stopped taking gold, penicillamine, or levamisole were randomly allocated to one of the alternative drugs and followed up for a minimum of one year. Concurrent studies of the effects of gold, penicillamine, and levamisole prescribed in 123 patients as the first second-line drug were used for comparison. No difference in toxicity or efficacy between primary and secondary use of gold or penicillamine was identified. Variation in the toxicity of levamisole could in part be accounted for by changes in the dose regimen over the four years of study. The length of the treatment-free interval between drugs did not influence subsequent development of toxicity.

These results suggest that an adverse reaction to one of the three second-line drugs studied should not prejudice the selection of another.
\end{abstract}

\section{Introduction}

Second-line drug treatment for rheumatoid arthritis is associated with considerable toxicity, which often prevents long-term treatment with a single agent. ${ }^{1-3}$ The disease may remain active for many years, and a sequence of second-line drugs may be needed. It is therefore important to establish the effect of order of administration of second-line drugs on the development of side effects and the efficacy of individual drugs. Results of previous retrospective studies on the effect of prior gold treatment on subsequent penicillamine treatment have been contradictory. ${ }^{4-11}$ We report a prospective study of patients who had stopped taking gold, penicillamine, or levamisole and were subsequently randomly allocated to one of the alternative drugs.

\footnotetext{
Centre for Rheumatic Diseases, Glasgow G4 0EH, and Department of Medicine, Glasgow Royal Infirmary

M M STEVEN, MRCP, senior registrar

J A HUNTER, MRCP, senior registrar

R M MURDOCH, BSC, systems analyst

H A CAPELL, MRCP, consultant physician
}

\section{Patients and methods}

We studied 88 patients with classical or definite rheumatoid arthritis. All had stopped taking a second-line drug because of toxicity or lack of effect ( 38 had previously received gold, 19 penicillamine, and 31 levamisole). A further second-line drug was indicated because of progressive inflammatory disease, and after a "wash-out" period they were randomly allocated to one of the alternative drugs. The treatmentfree interval allowed was three months unless extremely active disease necessitated earlier introduction of a second or third drug. When results from concurrent studies in 123 patients showed that levamisole was less effective and more toxic than the other drugs ${ }^{3}$ levamisole was given only to patients who had stopped taking both gold and penicillamine.

No patient was receiving corticosteroids at the time of study, but all continued non-steroidal anti-inflammatory drugs and general supportive measures. Patients were encouraged to persist with the treatment for six months unless unacceptable side effects occurred. All patients continuing treatment were monitored fortnightly or monthly for a minimum of one year.

Sodium aurothiomalate (Myocrisin) was given intramuscularly as a $10 \mathrm{mg}$ test dose followed by weekly injections of $50 \mathrm{mg}$ until a response was achieved. Thereafter $50 \mathrm{mg}$ injections were given fortnightly, then three-weekly and ultimately four-weekly. Penicillamine was started at a daily dose of $125 \mathrm{mg}$ and increased by $125 \mathrm{mg}$ at fortnightly or monthly intervals until response occurred or a maximum of $1000 \mathrm{mg}$ daily was reached. Levamisole was given initially as $150 \mathrm{mg}$ on three consecutive days weekly, but when results of multicentre studies became available this was reduced to $150 \mathrm{mg}$ weekly. If patients failed to respond to the low dose after six months the dose was increased to $150 \mathrm{mg}$ twice weekly and, if necessary, to $150 \mathrm{mg}$ on three consecutive days. Patients stopped taking the drugs when any of the following occurred:

(1) Proteinuria greater than $300 \mathrm{mg} /$ day when other causes had been excluded. If, when the proteinuria had settled, the patient agreed to a further trial reintroduction of the drug at a lower dose was tried. (2) Platelet count less than $150 \times 10^{9} / 1$ or white cell count less than $4 \times 10^{9} / 1$ on two consecutive occasions. In patients receiving penicillamine reintroduction of the drug at a dose of $125 \mathrm{mg}$ was tried if the platelet count returned promptly to normal. (3) Rash, mouth ulceration, myalgia, or gastrointestinal upset and either the patient refused to try rechallenge at a lower dose or the side effect recurred when the drug was reintroduced. (4) Deterioration of arthritis and the patient was unwilling to persevere.

A third drug was given to 26 patients who had stopping taking two of the drugs and in whom continuing disease activity necessitated further second-line treatment.

Appropriate non-parametric statistics were used throughout ${ }^{12}$ to test for significance. 


\section{Results}

The 88 patients studied comprised 20 men (median age 45 years, range 24-65) and 68 women (median age 49 years, range 27-74). The median duration of disease at the time of entry to the study was eight years (range 2-28).

The three groups of patients allocated to alternative second-line treatment (25 to gold (group G2), 39 to penicillamine (P2), and 24 to levamisole (L2)) were comparable in terms of age and duration of disease and initial haemoglobin concentration, erythrocyte sedimentation rate, and rheumatoid factor titres (Kruskal-Wallis test). Of the 38 patients who had previously received gold, 36 had stopped taking it because of toxicity and two because of inefficacy; of the 19 who had received penicillamine, 16 had stopped because of toxicity and three

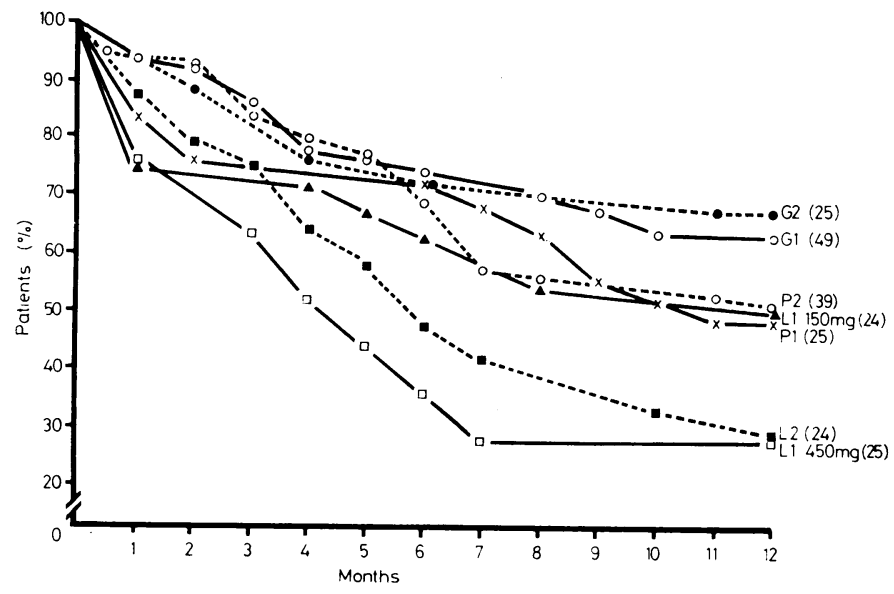

FIG 1-Cumulative drop-out rates among patients receiving second-line drugs. $\mathrm{G}=$ Gold, $\mathbf{P}=$ penicillamine, $\mathrm{L}=$ levamisole given as (1) first or (2) second drug. (Numbers of patients given in parentheses.) because of inefficacy; and of the 31 who had received levamisole, 25 had stopped because of toxicity and six because of inefficacy.

Figure 1 shows the proportions of patients who received treatment for one year, and includes the outcome of treatment in the 123 patients who received gold, penicillamine, or levamisole as their initial second-line drug (groups G1, P1, L1). ${ }^{3}$ There was no significant difference between the proportions who were still receiving treatment at one year when gold and penicillamine were given first or second. The variable dose of levamisole made comparison difficult: those patients receiving a low dose $(150 \mathrm{mg}$, given as the initial second-line drug (group L1)) were more likely to remain on treatment but did not derive comparable benefit. ${ }^{3}$ The proportions who after one year were still taking levamisole as initial treatment $(\mathrm{L} 1 ; 450 \mathrm{mg})$ and as second treatment (L2; variable dose 450-150 mg) were similar.

Figure 2 shows the observed and expected numbers of patients still receiving treatment at one year, subdivided according to the initial drug that they had received. Expected numbers were derived from the 123 patients taking the initial drugs (groups G1, P1, L1). Of the 38 patients who had stopped taking gold, 22 went on to receive penicillamine and 16 levamisole. At one year 12 patients were still receiving penicillamine (group P2) compared with an expected 11 and five were still receiving levamisole (group L2) (expected six). Six patients who had stopped taking both gold and penicillamine went on to take levamisole (group L3) and at one year one was still taking it (expected two). Ten patients who had stopped taking both gold and levamisole changed to penicillamine (group P3), of whom six continued treatment for at least one year (expected five). Similarly, fig 2 also shows the outcome in patients who first took penicillamine and levamisole.

The age and duration of disease were similar in patients who stopped treatment and in those who were able to continue (MannWhitney test).

Comparison of laboratory variables (haemoglobin concentration, erythrocyte sedimentation rate, platelet count, and rheumatoid factor titre) at the start and after one year of treatment showed significant improvement in all variables in patients who had received gold (group G2) for one year, and in haemoglobin concentration, erythrocyte sedimentation rate, and platelet count in patients taking penicillamine (group P2) (Wilcoxon matched pairs). Significant benefit could not

TABLE I-Reasons for withdrawal of drug during first year

\begin{tabular}{|c|c|c|c|c|c|c|}
\hline & \multicolumn{2}{|c|}{ Gold } & \multicolumn{2}{|c|}{ Penicillamine } & \multicolumn{2}{|c|}{ Levamisole } \\
\hline & $\begin{array}{c}\text { As second } \\
\text { drug } \\
\text { (group G2) } \\
(\mathrm{n}=25)\end{array}$ & $\begin{array}{c}\text { As third } \\
\text { drug } \\
\text { (group G3) } \\
(\mathrm{n}=5)\end{array}$ & $\begin{array}{c}\text { As second } \\
\text { drug } \\
(\underset{n}{(\mathrm{n}=39)})\end{array}$ & $\begin{array}{l}\text { As third } \\
\text { drug } \\
\text { (group } \mathrm{P} 3) \\
(\mathrm{n}=5)\end{array}$ & $\begin{array}{c}\text { As second } \\
\text { drug } \\
(\underset{n}{(\mathrm{n}=0 \mathrm{p}=24)})\end{array}$ & $\begin{array}{c}\text { As third } \\
\text { drug } \\
\text { (group L3) } \\
(\mathrm{n}=6)\end{array}$ \\
\hline Leucopenia & 1 & & & & 1 & \\
\hline Thrombocytopenia & 2 & & 4 & & & \\
\hline $\begin{array}{l}\text { Eosinophilia } \\
\text { Proteinuria }\end{array}$ & 1 & & 5 & & & \\
\hline Rash & & 1 & 3 & & 7 & 2 \\
\hline Mouth ulcers & 1 & 1 & 2 & & & \\
\hline Nausea/vomiting & & & 2 & & 2 & \\
\hline $\begin{array}{l}\text { Diarrhoea } \\
\text { Myalgia }\end{array}$ & & & & & 3 & 1 \\
\hline Depression & & & & & 1 & \\
\hline Exacerbation of arthritis & & & & & 1 & \\
\hline Inefficacy & 2 & & 2 & 1 & 2 & \\
\hline Defaulted & 1 & & 1 & 2 & & \\
\hline Total & 8 & 2 & 19 & 3 & 17 & 4 \\
\hline
\end{tabular}

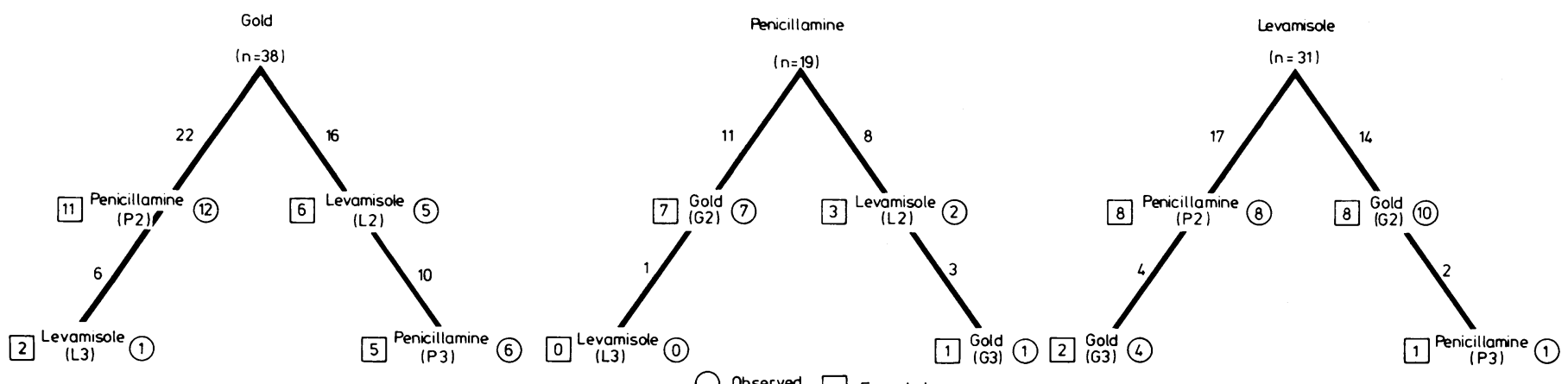

$\bigcirc$ Observed $\square$ Expected

FIG 2-Observed and expected numbers of patients still taking second-line treatment at one year. 
be shown with levamisole (group L2), though the trend was favourable. The numbers of patients who took a third drug (groups G3, P3, L3) were too small for meaningful analysis, but the trend was again towards improvement.

Table I shows the reasons for stopping second and third drugs. These were comparable with those seen when the drugs were used in the first instance. ${ }^{3}$ Comparison of the reason for stopping the first drug with that for stopping the second drug at all stages of follow-up showed that 10 patients stopped the two drugs for the same reason (rash (four), inefficacy (two), leucopenia (one), thrombocytopenia (one), proteinuria (one), myalgia (one)) and 42 stopped for different reasons.

The duration of the interval between the first and second drugs (wash-out period) showed no relation to the time for which the second drug was taken or to the chance of recurrence of the same side effect (table II). Further data show that 36 patients are still taking a second drug, which constitutes in some instances more than five years of effective treatment. Table III shows the outcome of using a second drug in patients who stopped the first drug because of proteinuria, rash, leucopenia, thrombocytopenia, or inefficacy.

TABLE II-Reasons for withdrawal and interval between first and second drugs

\begin{tabular}{|c|c|c|c|}
\hline & \multicolumn{2}{|c|}{$\begin{array}{l}\text { Reasons for withdrawal of first } \\
\text { and second drugs: }\end{array}$} & \multirow{2}{*}{$\begin{array}{l}\text { Continued } \\
\text { treatment with } \\
\text { second drug }\end{array}$} \\
\hline & Same & Different & \\
\hline $\begin{array}{l}\text { No of patients } \\
\text { Interval between drugs (months): }\end{array}$ & 10 & 42 & 36 \\
\hline $\begin{array}{l}\text { Range } \\
\text { Median } \\
\text { Mean }\end{array}$ & $\begin{array}{l}3-24 \\
3 \cdot 5 \\
7\end{array}$ & $\begin{array}{c}1-36 \\
5 \\
10\end{array}$ & $\begin{array}{c}1-27 \\
4 \\
7\end{array}$ \\
\hline
\end{tabular}

TABLE III-Outcome of using second drug in patients who had previously stopped taking a different drug

\begin{tabular}{|c|c|c|c|c|c|}
\hline $\begin{array}{l}\text { Reason for first } \\
\text { withdrawal }\end{array}$ & & & $\begin{array}{c}\text { No of } \\
\text { patients }\end{array}$ & $\begin{array}{l}\text { No who } \\
\text { continued taking } \\
\text { second drug }\end{array}$ & $\begin{array}{l}\text { Time for which } \\
\text { second drug taken } \\
\text { (months) }\end{array}$ \\
\hline Proteinuria & .. & .. & 12 & 6 & $12-45$ \\
\hline Rash .. & $\therefore$ & $\therefore$ & 30 & 10 & $12-54$ \\
\hline Leucopenia $\quad \ldots$ & $\because$ & $\because$ & 15 & 10 & $12-30$ \\
\hline Thrombocytopenia & $\because$ & $\therefore$ & 5 & 2 & $12-34$ \\
\hline Inefficacy $\quad \ldots$ & $\because$ & $\because$ & 11 & 5 & $12-62$ \\
\hline
\end{tabular}

\section{Discussion}

The usefulness of second-line drugs in the management of patients with rheumatoid arthritis is limited by their toxicity. ${ }^{1-3}$ These drugs produce symptomatic benefit but need to be continued for 18 months or more before radiological improvement can be documented. ${ }^{13}$ When treatment is stopped because of adverse reaction relapse almost always occurs, although the period of remission may vary. ${ }^{14}$ In the absence of more effective and less toxic remedies optimum use of currently available drugs is imperative.

The suggestion that the incidence of penicillamine toxicity is increased in patients who previously experienced gold toxicity ${ }^{4} 7-9$ has been challenged but has obvious implications for the order of treatment with second-line drugs. In this study patients derived comparable benefit whether the drugs were given first or second (or third, although numbers in these groups were small), and the patterns of toxicity were similar irrespective of order. Recurrence of the same side effect with the second drug was unusual, and large numbers would be required to establish whether individual toxicities recurred more often than expected. Scrupulous clinical and laboratory monitoring of patients is always mandatory, but we have no evidence that "drop outs" are at greater risk of toxicity when a further second-line drug is used. HLA typing of patients suffering recurrent side effects has not yet been carried out, and the interesting hypothesis ${ }^{15}$ that some patients are genetically predisposed to certain adverse reactions cannot be confirmed.

The role of levamisole as a second-line drug in the treatment of rheumatoid arthritis is uncertain, ${ }^{3}$ and variation in the dose used over the four-year study period made interpretation of the results difficult. Concurrent studies suggest that low-dose levamisole $(150 \mathrm{mg} /$ week) is less effective and that the higher dose $(450 \mathrm{mg} /$ week) is unacceptably toxic when compared with gold or penicillamine. Therefore, levamisole is recommended only in patients in whom gold and penicillamine have failed.

It has been suggested that a short interval between gold and subsequent penicillamine treatment leads to increased toxicity with the penicillamine, ${ }^{9}$ but our study does not confirm this. We recommend a three-month wash-out period, but in some cases in this study pronounced disease activity necessitated earlier introduction of the second drug. Nevertheless, no relation was found between the duration of the wash-out period and the subsequent development of toxicity.

This prospective study found no influence of prior gold, penicillamine, or levamisole treatment on the subsequent efficacy or toxicity of one of the alternative drugs.

J A Hunter is an Arthritis and Rheumatism Council lecturer. We thank Mrs M Tucker for typing the manuscript.

\section{References}

1 Anonymous. Fifty years of gold in rheumatoid arthritis. $\operatorname{Br} M e d \mathcal{F} 1979$;i: 289-90.

2 Weiss AS, Markinson JA, Weiss MS, Kammerer WH. Toxicity of Dpenicillamine in rheumatoid arthritis-a report of 63 patients including 2 with aplastic anaemia and one with the nephrotic syndrome. $A m \mathcal{F} M e d$ $1978 ; 64: 114-20$.

${ }^{3}$ Capell HA, Hunter JA, Rennie JAN, Murdoch RM. Levamisole-a possible alternative to gold and penicillamine in the long-term treatment of rheumatoid arthritis ? F Rheumatol (in press).

4 Day AT, Golding JR. Hazards of penicillamine therapy in the treatment of rheumatoid arthritis. Postgrad Med $\mathcal{F} 1974 ; 50$,suppl $2: 71$.

${ }^{5}$ Dippy JE. Penicillamine in rheumatoid arthritis-a 2 year retrospective study in 70 patients. Br $\mathcal{F}$ Clin Pract 1977;31:5.

6 Tsang IK, Patterson CA, Stein HB, Robinson HS, Ford DK. DPenicillamine in the treatment of rheumatoid arthritis. Arth Rheum $1977 ; 20: 666-70$.

${ }^{7}$ Hill HF. Penicillamine in rheumatoid arthritis: adverse effects. Scand $\mathcal{F}$ Rheumatol 1979;suppl 28:94-9.

8 Webley $M$, Coomes EN. Is penicillamine therapy in rheumatoid arthritis influenced by previous therapy with gold ? $\mathrm{Br}$ Med $\mathcal{F} 1979 ; \mathrm{ii}: 91$.

${ }^{9}$ Dodd MJ, Griffiths ID, Thompson M. Adverse reactions to D-penicillamine after gold toxicity. $\mathrm{Br}$ Med f 1980;280:1498-500.

${ }^{10}$ Smith PJ, Swinburn WR. Adverse reactions to D-penicillamine after gold toxicity. Br Med f 1980;281:617.

11 Husain Z, Runge LA. Treatment complications of RA with gold, hydroxychloroquine, D-penicillamine, and levamisole. $\mathcal{F}$ Rheumatol 1980;7: 825-30.

12 Siegel S. Non-parametric statistics for the behavioral sciences. Kogakusha, Tokyo: McGraw-Hill, 1956.

13 Sigler JW, Bluhm GB, Duncan H, et al. Gold salts in the treatment of rheumatoid arthritis. Ann Int Med 1974;80:21-6.

14 Gottlieb NL. Chrosotherapy. Bull Rheum Dis 1976-77;27:912-7.

15 Wooley PH, Griffin MB, Panayi GS, Batchelor JR, Welsh KI, Gibson TJ. HLA-Dr antigens and toxic reactions to sodium aurothiomalate and D-penicillamine in patients with rheumatoid arthritis. $N$ Engl $₹ \mathrm{Med}$ $1980 ; 303: 300-2$.

(Accepted 30 September 1981)

MOISTENING MEDICINES-There can be no such difference found amongst moistening medicines, that they should surpass the second degree. For seeing all medicines are either hot or cold, neither heat nor cold, seeing they are extremes, can consist with moisture, for the one dries it up, the other condensates it. Phylosophers therefore call moisture and dryness, passive qualities, yet have they their operation likewise; for moist medicines lenifies and make slippery, ease the cough, and help the roughness of the throat. These operations are proper to medicines moist in the first degree. Those which are moister, take away naturally strength, help the sharpness of humours, make both blood and spirits thicker, looses the belly, and fits it for purgation. The immoderate or indiscreet use of them dulls the body, and makes it unfit for action (Nicholas Culpeper (1616-54) The Complete Herbal, 1850.) 